\title{
Eye Salvage with Intra-Arterial and Intra-Vitreal Chemotherapy in Patients with Retinoblastoma: 8-Year Single-Institution Experience in Colombia
}

\author{
María Elena González ${ }^{a}$ Martha Lia Gaviria ${ }^{b}$ Mariana López ${ }^{c}$ \\ Pablo Andrés Escudero ${ }^{d}$ Andrés Bravo ${ }^{\text {e Sergio Alberto Vargas }}{ }^{d}$ \\ aOcular Oncology Service, Hospital San Vicente Fundación, Universidad de Antioquia, Medellín, Colombia; \\ bPaediatric Ophthalmology Service Hospital San Vicente Fundación, Universidad de Antioquia, Medellín, Colombia; \\ 'Ophthalmology Service, Hospital San Vicente Fundación, Medellín, Colombia; 'Department of Interventional \\ Neuroradiology, Hospital San Vicente Fundación, Medellín, Colombia; 'eMedical School, Universidad CES, \\ Medellín, Colombia
}

\section{Keywords}

Chemotherapy $\cdot$ Intra-arterial infusions $\cdot$ Intraocular

tumors · Ocular oncology $\cdot$ Retinoblastoma

\begin{abstract}
Introduction: Intra-arterial chemotherapy (IAC) is useful for eye preservation in advanced retinoblastoma $(\mathrm{Rb})$. Intra-vitreal chemotherapy (IvitC) is the latest treatment for vitreous seeds. Methods: The present study is a retrospective assessment of 100 eyes, treated with primary or secondary IAC alone or with IvitC. We evaluated demographic and clinical variables, eye salvage, associated adverse events, and patient survival. Data were analyzed using descriptive statistics. Kaplan-Meier survival curves and Cox hazard ratios were utilized to assess the effect of demographic and clinical variables over eye salvage. Results: Bilateral Rb was observed in $61 \%$ of patients, and $57 \%$ of eyes received secondary treatment. Forty eyes needed intra-arterial plus IvitC and 62 presented advanced disease (group D and E). Three- and 5-year ocular survival probabilities were 75 and $68 \%$. We found a higher risk in group $D$ and $E$ eyes and those requiring 2 or more routes for ophthalmic artery catheterization. Patients coming from other countries also showed increased risk. Us-
\end{abstract}

ing primary or secondary treatment, or IvitC, did not affect this risk. Overall rates of survival and eye salvages were 98.8 and $73 \%$, and we had a $100 \%$ catheterization success and none ophthalmic arterial occlusions. Conclusions: In an upper middle-income country such as Colombia, a specialized institution counting with therapeutic alternatives and a multidisciplinary team can reach rates of patient survival and eye salvage similar to those of high-income countries.

(c) 2021 S. Karger AG, Basel

\section{Introduction}

Retinoblastoma $(\mathrm{Rb})$ is the primary-malignant-intraocular tumor most frequently diagnosed during childhood [1]. The treatment of these tumors has gone from using enucleation and external beam radiation (EBR) as only alternatives to the use of intravenous chemotherapy (IVC), and finally, intra-arterial chemotherapy (IAC) [24]. IAC not only improved eye salvage in patients with advanced disease but also reduced the systemic adverse events when compared to IVC $[5,6]$. IAC is currently used in over 45 countries [7], but its effect over tumors with vitreous seeds is limited. For this reason, intra-vitre- 
al chemotherapy (IvitC) has gained popularity for treating patients with extensive vitreous seeds, improving eye salvage rates for these patients [8-10].

Most $\mathrm{Rb}$ cases are diagnosed in developing countries (80-90\%) [11], and $\mathrm{Rb}$ mortality is close to $42 \%$ worldwide [12]. In Colombia, an upper middle-income country, no study has assessed IAC or IvitC as treatments for $\mathrm{Rb}$. This work employs the Hospital San Vicente Fundación (HSVF) dataset to evaluate the effect of IAC and IvitC on eye salvage, survival, and adverse events of $\mathrm{Rb}$ patients. These therapies have been used in this center for 8 and 6 years, respectively.

\section{Methods}

The dataset in this retrospective cohort study was collected prospectively for 8 years and 4 months. The patients included in this analysis had suffered unilateral or bilateral $\mathrm{Rb}$ and were treated with IAC between August 2011 and December 2019 at HSVF in Medellín, Colombia. Patients with corneal opacity, secondary glaucoma, extraocular extension, optic nerve involvement, and blood dyscrasias were excluded. Parents or guardians were informed about the procedure's risks and asked for informed consent. The Ethics Committee of the institution approved the study.

The HSVF Ophthalmology Team used indirect ophthalmoscopy, fundus drawing, and pictures taken with a retinal RetCam ${ }^{\circledR}$ Camera (Clarity, Pleasanton, CA, USA) for the assessments. The patients received general anesthesia during these evaluations.

Treatment decisions were made by an interdisciplinary group, including Interventional Neuroradiology, Pediatric Oncology, and Ophthalmology. IAC was conducted as described elsewhere $[12,13]$. Melphalan was used at doses ranging between 3 and 7.5 $\mathrm{mg}$, depending on weight and age. One milligram of topotecan or carboplatin at doses between 20 and $30 \mathrm{mg}$ was applied in addition to melphalan for patients with extensive disease or vitreous seeding. During simultaneous bilateral therapies (Tandem), the doses were equally divided between both eyes. IAC was performed every 3 weeks. Bridge therapy was conducted in patients younger than 3 months. This therapy began with IVC at diagnosis, followed by IAC once the patient reached this age [13]. Secondary treatment refers to patients treated at a different institution with any therapy who came to our institution with poor response or relapse [14]. Rescue IAC relates to patients who received IAC at our institution and received a second set of IAC after relapsing [14]. IvitC, as described by Munier et al. [10], was used for recurrent or persistent vitreous seeds, or retinal or subretinal diseases were IAC was contraindicated. Weekly IvitC injections were applied, including melphalan, topotecan, and carboplatin at doses of 20-30, 10-20, and $4 \mathrm{mcg}$ per eye, respectively, and the response was evaluated after 3 injections. By this point, IvitC was suspended or continued for up to 8 injections depending on patient response.

The effect of demographic, clinical, and treatment variables on patients' survival and eye salvage rates were evaluated. These variables included eyes were classified according to disease severity using the Children Oncology Group (COG) version of the International Classification of Retinoblastoma (ICRB) $[15,16]$ and Rb recurrences according to the $\mathrm{Rb}$ classification at relapse (RSUClassification) [17]. Treatment-associated variables were catheterization number, drug administration route, drug type, and concomitance with other treatments such as IvitC. Previous local therapies and systemic chemotherapy use were also included. Demographic variables such as age at diagnosis, sex and origin, and clinical variables like laterality, clinical sings, follow-up time, and indication for IAC were also included. During these evaluations, visual acuity and adverse events resulting from the treatments were analyzed, besides patients' survival and eye salvage rates. Adverse events were divided into external or periocular, intraocular, and systemic adverse events.

The data were collected in Excel (Microsoft Corp) and analyzed in the RStudio version (1.3.1056) [18]. Descriptive statistics were used to report the median and interquartile range (IQR) of continuous variables (with 25 th and 75 th centiles given as the IQR). Number and percentage were used to describe categorical variables. Kaplan-Meier survival curves were analyzed using the "survfit" and "Surv" functions of the "survival" package (version 2,3-3) [19]. For this analysis, enucleations and eyes treated with external beam radiation therapy were considered treatment failures (events). Curves were visualized using the "ggsurvplot" from the "survminer" package (version 0.4.8.999) [20]. Multivariable analysis was performed to determine the risk of treatment failure associated with the evaluated factors using a Cox proportional regression model. The Cox proportional regression was obtained using the function "coxph" from the "survival" package (version 2,3-3) [19].

\section{Results}

In this study, 100 eyes representing 85 patients were included. The median age was 8.7 (IQR, 4.5-18.6) months at diagnosis. Sixty eyes (60\%) received IAC alone, and 40 (40\%) received IAC + IvitC, after 2013 when IvitC became available in HSVF. Thirteen patients (15\%) came from other countries, and leukocoria and strabismus were the most predominant clinical signs (Table 1).

Out of the 85 patients, $52(61.2 \%)$ had bilateral $\mathrm{Rb}$, and 29 had a single eye $\mathrm{Rb}$. Group D was the predominant group with 51 eyes (51\%), followed by group C with 27 eyes (27\%), group $\mathrm{E}$ with 11 eyes (11\%), and group B with 10 eyes (10\%). One eye from group A was included in the study because it did not respond after 2 sessions of local treatment, and the tumor growth was threatening the fovea. However, this eye was bound to eyes from group $B$ and analyzed as eyes from ICRB group A/B (Table 1). Regarding the type of treatment, 43 eyes $(43 \%)$ received primary treatment, and 57 eyes (57\%) received secondary treatment. From the 85 patients, 55\% received previous IVC, and $45 \%$ received prior local therapy (Table 1 ). Bilateral IAC was used in 15 patients, and 14 of them were treated with tandem therapy. Thirty-one eyes (31\%) had rescue IAC, and 1 patient received bridge therapy. 
Table 1. Demographic and clinical variables of the patients diagnosed with $\mathrm{Rb}$ and treated with IAC

\begin{tabular}{|c|c|}
\hline Variable & $\begin{array}{l}N(\%) / \text { median } \\
\text { (IQR range) }\end{array}$ \\
\hline Age, months, $(N=85$ patients $)$ & $8.70(4.53-18.55)$ \\
\hline Unilateral & $14.43(6.66-32.93)$ \\
\hline Bilateral & $6.21(3-11.88)$ \\
\hline \multicolumn{2}{|l|}{$\operatorname{Sex}(N=85$ patients $)$} \\
\hline Male & $42(49.4)$ \\
\hline Female & $43(50.6)$ \\
\hline \multicolumn{2}{|l|}{ Country of origin ( $N=85$ patients $)$} \\
\hline Colombia & $72(84.7)$ \\
\hline Other countries & $13(15.3)$ \\
\hline \multicolumn{2}{|l|}{ Clinical sing ( $N=85$ patients $)$} \\
\hline Leukocoria & $47(55.3)$ \\
\hline Strabismus & $23(27.0)$ \\
\hline Visual acuity reduction or nystagmus & $5(5.9)$ \\
\hline Ophthalmoscopy & $3(3.5)$ \\
\hline Other & $7(8.2)$ \\
\hline \multicolumn{2}{|l|}{ Laterality ( $N=85$ patients $)$} \\
\hline Unilateral & $33(38.8)$ \\
\hline Bilateral & $52(61.2)$ \\
\hline \multicolumn{2}{|l|}{ ICRB $(N=100$ eyes $)$} \\
\hline Group A & $1(1.0)$ \\
\hline Group B & $10(10.0)$ \\
\hline Group C & $27(27.0)$ \\
\hline Group D & $51(51.0)$ \\
\hline Group E & $11(11.0)$ \\
\hline \multicolumn{2}{|l|}{ Treatment indication ( $N=100$ eyes $)$} \\
\hline Primary & $43(43.0)$ \\
\hline Secondary & $57(57.0)$ \\
\hline \multicolumn{2}{|l|}{ Previous treatment ( $N=100$ eyes $)$} \\
\hline IVC & $55(55.0)$ \\
\hline Local treatment & $45(45.0)$ \\
\hline IvitC & $8(8.0)$ \\
\hline IAC & $5(5.0)$ \\
\hline Brachytherapy & $1(1.0)$ \\
\hline
\end{tabular}

ICRB, International Classification of Retinoblastoma; IVC, intravenous chemotherapy; IvitC, intra-vitreal chemotherapy; IAC, intra-arterial chemotherapy; IQR, interquartile range; $\mathrm{Rb}$, retinoblastoma.

The number of catheterizations performed was 513, with a median of 5 (IQR, 3-7) per eye. From these, 444 (86.5\%) were through the internal carotid, 64 (12.5\%) through the external carotid, and 5 (1\%) through the vertebral artery. Balloon occlusion was used in 1 patient in whom catheterization through the ophthalmic artery was not feasible. Melphalan with topotecan was the most common drug-regime in IAC, and the melphalan-meancumulative dose was $20 \mathrm{mg}$ (IQR $12.8-38.3 \mathrm{mg}$ ) per patient. The number of IvitC was 233, with a median of 5
(IQR 4-8) per eye. The melphalan-mean-cumulative dose was $150 \mathrm{mcg}$ (IQR of $120-225 \mathrm{mcg}$ ) per patient for IvitC.

The overall survival rate was $98.8 \%$, and the median for the follow-up time was 29 (IQR, 16-59) months. Fifteen patients had follow-up shorter than 12 months. Of these patients, 10 were enucleated; 2 lived abroad, and contact was lost during follow-up as their insurance companies did not authorize follow-up visits, and 3 entered the program in 2019 and had not completed 1 year by the study end. One of the patients living abroad rejected enucleation, which resulted in metastases and death of the patients. This patient had his right eye previously enucleated and had received 10 cycles of systemic chemotherapy. When we met him, his remaining eye had a group $\mathrm{E}$ $\mathrm{Rb}$, which was treated with IAC (\#7) and IvitC (\#6). After 20 months of follow-up and recurrent disease, extensive ciliary body involvement was diagnosed. We recommended enucleation, but his parents refused the procedure, and after that we lost contact with the family. We found that he died from metastasis through the social worker at HSVF, but could not communicate with his family for detail on the site of metastasis and cause of death.

The three- and 5-year ocular survival probability was 0.75 (95\% CI 0.66-0.85), and 0.68 (95\% CI 0.57-0.80), respectively (Fig. 1a). The ICRB classification affected the probability of ocular survival ( $p$ 0.00042) (Fig. 1b), and patients from other countries had a significantly lower ocular survival probability when compared with patients from Colombia ( $p$ 0.0037) (Fig. 1c). The use of the internal carotid artery resulted in a better likelihood of ocular survival when compared with external carotid or $>1$ route ( $p$ 0.033) (shown in Fig. 1d). Age, indication for IAC, the medication used, and the use of IvitC did not associate with better ocular survival probabilities $(p>$ $0.05)$.

Cox proportional regression model showed that patients from other countries were $\times 2.55$ (95\% CI 0.99 6.56) more at risk of eye enucleation when compared with patients from Colombia ( $p$ 0.052). Similarly, eyes in the ICRB groups D and $\mathrm{E}$ were $\times 9.14$ (95\% CI 1.16-72.21, $p 0.036)$ and $\times 34.90(3.76-323.92, p 0.002)$ more at risk as compared with eyes from group $\mathrm{C}$. Eyes in group A/B were not included in this analysis as they represented no risk of enucleations. For the route of administration for IAC, patients who needed 2 or more routes had the worst outcome with a hazard ratio $\times 2.80(95 \%$ CI $1.17-6.71)$ higher $(p 0.021)$ than those in which the internal carotid artery. No differences were evidenced between using the 


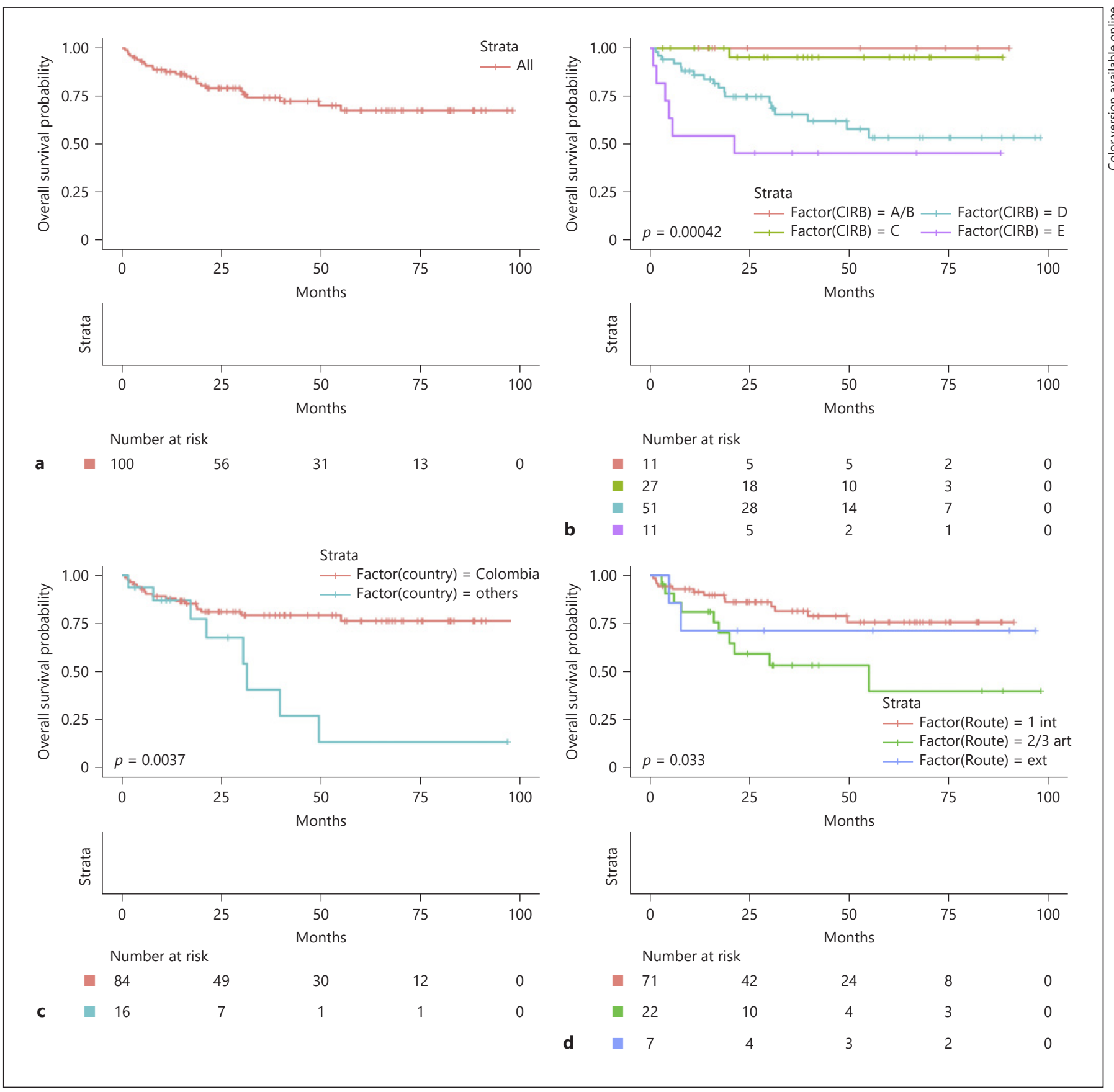

Fig. 1. a Overall eye survival. b Eye survival, according to the ICRB group. c Eye survival among eyes from Colombian patients versus foreign. $\mathbf{d}$ Eye survival according to the route used. IRCB, International Classification of Retinoblastoma.

internal or external carotid artery as administration route ( $p$ 2.33). Patients who needed a 3-drug combination (melafan + topotecan + carboplatin) were more at risk than those who needed only 1 drug, as they showed a hazard ratio $\times 5.65(95 \%$ CI 1.17-27.22) higher ( $p 0.031)$.
Age, indication for IAC, and IvitC use were not associated with a higher risk of treatment failure $(p>0.05)$ (Table 2).

Contrary to what we expected, we found no differences in the eye salvage ratios for those that received IAC as 
Table 2. Multivariable analysis for the association of treatment failure with demographic and clinical variables for patients diagnosed with $\mathrm{Rb}$ and treated with IAC

\begin{tabular}{|c|c|c|}
\hline & $\begin{array}{l}\text { Hazard ratio } \\
\text { HR (CI 95\%) }\end{array}$ & $\begin{array}{l}\text { Hazard } \\
\text { ratio dif- } \\
\text { ferences } \\
\text { ( } p \text { value) }\end{array}$ \\
\hline \multicolumn{3}{|l|}{ Age at diagnosis } \\
\hline $\begin{array}{l}\text { Below or equal the median } \\
\text { Above the median }\end{array}$ & $\begin{array}{c}1 \\
1.01(0.34-3.04)\end{array}$ & 0.984 \\
\hline \multicolumn{3}{|l|}{ Country } \\
\hline $\begin{array}{l}\text { Colombia } \\
\text { Other countries }\end{array}$ & $\begin{array}{l}1 \\
2.55(0.99-6.56)\end{array}$ & 0.052 \\
\hline \multicolumn{3}{|l|}{ CIRB } \\
\hline $\mathrm{C}$ & 1 & \\
\hline $\mathrm{D}$ & $9.14(1.16-72.21)$ & 0.036 \\
\hline $\mathrm{E}$ & $34.90(3.76-323.92)$ & 0.002 \\
\hline \multicolumn{3}{|l|}{ Indication for IAC } \\
\hline Primary treatment & 1 & 0.989 \\
\hline Secondary treatment & $1.01(0.34-3.02)$ & \\
\hline \multicolumn{3}{|l|}{ Medication used in IAC } \\
\hline Melfalan & 1 & \\
\hline Melfalan + topotecan & $3.50(0.96-12.84)$ & 0.058 \\
\hline $\begin{array}{l}\text { Melfalan }+ \text { topotecan }+ \\
\text { carboplatin }\end{array}$ & $5.65(1.17-27.22)$ & 0.031 \\
\hline \multicolumn{3}{|l|}{ Route } \\
\hline Internal carotid & 1 & \\
\hline External carotid & $2.80(0.52-14.56)$ & 0.233 \\
\hline 2 or 3 arteries & $2.80(1.17-6.71)$ & 0.021 \\
\hline \multicolumn{3}{|l|}{ IvitC use } \\
\hline No & 1 & 0.260 \\
\hline Yes & $0.60(0.25-1.46)$ & \\
\hline
\end{tabular}

ICRB, International Classification of Retinoblastoma; IAC, intra-arterial chemotherapy; IvitC, intra-vitreal chemotherapy; $\mathrm{Rb}$, retinoblastoma.

a secondary treatment or among eyes treated and not treated with IvitC. We believe that the survival probability increased in these eyes due to the use of IAC and IvitC, as worst results were anticipated for these eyes.

Overall, 27 eyes had a treatment failure, 25 were enucleated and 3 received external beam radiation therapy because their parents refused enucleation. From these 3 radiated eyes, 2 could be preserved during a 25 -month follow-up, and the other was finally enucleated due to persistent disease. We had 34 relapses, 20 intraretinal, 11 intra-vitreal, 2 subretinal, and 1 ciliary body relapse. Thirty-one eyes were treated with rescue IAC.

We have the pathology results of 15 out of 25 eyes enucleated, as they were enucleated at our institution. Six (40\%) had risk factors for metastasis, including 5 with massive choroidal invasion and 1 with ciliary body invasion. All of these patients received adjuvant systemic chemotherapy, and none presented metastases during follow-up.

Forehead hyperemia and choroidal vascular occlusion were the predominant adverse events observed in $20 \%$ of the eyes. Among the systemic adverse events, 8 patients (9.4\%) presented contrast media allergies without hemodynamic repercussion, and 5 patients had neutropenia. Three of them were grade 4 , one was grade 3 , and one was grade 2 . None of these patients required transfusion. All patients, including the international ones, had blood tests 2 days before each IAC or IvitC to determine their hematologic status (Table 3 ).

We reported 1 case of endophthalmitis among patients who received IvitC. This patient presented red-eye with pain and vitreitis $48 \mathrm{~h}$ after the sixth melphalan + topotecan injection. The eye was treated with 3 doses of intravitreal vancomycin + ceftazidime, and a Staphylococcus epidermidis was isolated. The infection signs decreased, but the vitreal opacity persisted, and since the fundus examination could not be performed, we decided to enucleate.

Visual acuity was evaluated in 42 eyes (42\%), being $20 / 40$ or better in $75 \%$ of group B eyes, $44 \%$ of group C eyes, and $27 \%$ of group D and $\mathrm{E}$ eyes. Visual acuity was below $20 / 200$ in $25 \%$ of group B eyes, $37 \%$ of group C eyes, and $64 \%$ of groups D and $\mathrm{E}$ eyes.

\section{Discussion}

The present study is the first report describing the use of IAC ( 8 years and 4 months-experience) and IvitC (6 years and 8 months-experience) for $\mathrm{Rb}$ in Colombia. We found 3 - and 5-year ocular survival probabilities of 0.75 (95\% CI 0.66-0.85), and 0.68 (95\% CI 0.57-0.80), which are high, considering Colombia is a upper middle-income country. The disease was advanced in $62 \%$ of the evaluated eyes (groups D and E), and 57\% needed secondary treatment. The eye salvage rate among patients with advanced disease was $61 \%$, and only 1 patient died of metastatic disease. Catheterization of the ophthalmic artery was successful in all patients, and none presented ophthalmic artery occlusion. During 1 procedure, the balloon occlusion technique was necessary.

The population of Colombia is nearly 49 million, and no studies describing the prevalence of $\mathrm{Rb}$ are available. Nearly $95 \%$ of this population has health insurance through a solidarity Health Care System, in which people 
Table 3. Complications of treatment with IAC from 513 catheterizations in 100 eyes

\begin{tabular}{|c|c|c|c|}
\hline $\begin{array}{l}\text { Adverse events* } \\
(N=513 \text { catheterizations in } 100 \text { eyes })\end{array}$ & $N$ & $\begin{array}{l}\text { Percentage } \\
\text { (\% per } 513 \text { catheterizations) }\end{array}$ & {$[\% \text { per } 100 \text { eyes }]^{*}$} \\
\hline \multicolumn{4}{|l|}{ External and periocular } \\
\hline Forehead hyperemia & 20 & $(3.9)$ & {$[20.0]$} \\
\hline Loss of eyelashes & 11 & $(2.1)$ & {$[11.0]$} \\
\hline Eyelid edema & 10 & $(1.9)$ & {$[10.0]$} \\
\hline Strabismus & 2 & $(0.4)$ & {$[2.0]$} \\
\hline \multicolumn{4}{|l|}{ Intraocular } \\
\hline Choroidal vascular occlusion & 20 & $(3.9)$ & {$[20.0]$} \\
\hline Ophthalmic artery spasm & 6 & $(1.2)$ & {$[6.0]$} \\
\hline Retinal hemorrhage & 5 & $(1.0)$ & {$[5.0]$} \\
\hline Retinal detachment & 4 & $(0.8)$ & {$[4.0]$} \\
\hline Vitreous hemorrhage & 4 & $(0.8)$ & {$[4.0]$} \\
\hline Optical neuropathy & 2 & $(0.4)$ & {$[2.0]$} \\
\hline Venous retinal branch occlusion & 1 & $(0.2)$ & {$[1.0]$} \\
\hline Ophthalmic artery occlusion & 0 & $(0.0)$ & {$[0.0]$} \\
\hline Central retinal artery occlusion & 0 & $(0.0)$ & {$[0.0]$} \\
\hline Systemic $* N=85$ & $\mathrm{~N}$ & (\% per 513 catheterizations) & [\% per 85 patients] \\
\hline Contrast media allergies & 8 & $(1.5)$ & {$[9.4]$} \\
\hline Neutropenia & 5 & $(1.0)$ & {$[5.9]$} \\
\hline Femoral artery thrombosis & 2 & $(0.4)$ & {$[2.4]$} \\
\hline Cerebral artery thrombosis & 1 & $(0.2)$ & {$[1.2]$} \\
\hline Bronchospasm & 1 & $(0.2)$ & {$[1.2]$} \\
\hline
\end{tabular}

IAC, intra-arterial chemotherapy; IvitC, intra-vitreal chemotherapy. ${ }^{*}$ Number of adverse events per eye might be more than one.

with higher income (60\%) pay more, and people with lesser income (40\%) are subsidiaries [21]. HSVF has agreements to attend patients from several insurance companies, covering an heterogeneous patient population from all income status. Any patient diagnosed with $\mathrm{Rb}$ has access to the treatments reported in this article, but access might take longer due to insurance procedures.

During 2019, the HSVF ophthalmology team surveyed the main centers of ocular oncology in Colombia and found that nearly 45 new $\mathrm{Rb}$ cases were observed per year. The 2-year survival rate for $\mathrm{Rb}$ patients was around $91 \%$ [22].

During our evaluations, we received 41 patients ( 42 eyes) with $\mathrm{Rb}$ diagnosis in addition to the 85 evaluated patients. These patients were not included in our evaluations as all of them needed enucleation and did not receive IAC. Six of the eyes were unilateral group D with massive vitreal seed, and the rest group E glaucoma, extraocular disease and vitreal hemorrhage. In conclusion, $29.6 \%$ of patients with $\mathrm{Rb}$ diagnosis were not treated with IAC.
Increasing eye salvage rate and patient survival, while avoiding metastasis, and enucleation are the main goals of $\mathrm{Rb}$ treatments [23]. Survival in high-income countries is between 95 and 100\% [24-26], but middle-income and low-income countries have lower survivals, that is, $79 \%$, and $40 \%$, respectively [23].

A low number of studies evaluating IAC and IvitC are currently available in Latin America. In Argentina, Chantada and colleagues (2018) reported that IAC alone resulted in a decreased number of eyes needing enucleation and EBR. According to this study, 61 out of 97 evaluated eyes $(63 \%)$ had no need for enucleation and EBR. However, this study used IvitC in only 3 patients [27]. Similarly, in Mexico, Leal et al. [28] reported a rate of eye salvage of $55 \%$ in 11 single eyes treated with IAC. We observed higher eye salvage rates than those reported for Argentina and Mexico, even considering that eyes from group E were not included in either of these studies. Our higher eye salvage rates likely resulted from the increased use of IvitC and the higher success rate of catheterization (Fig. 2). 


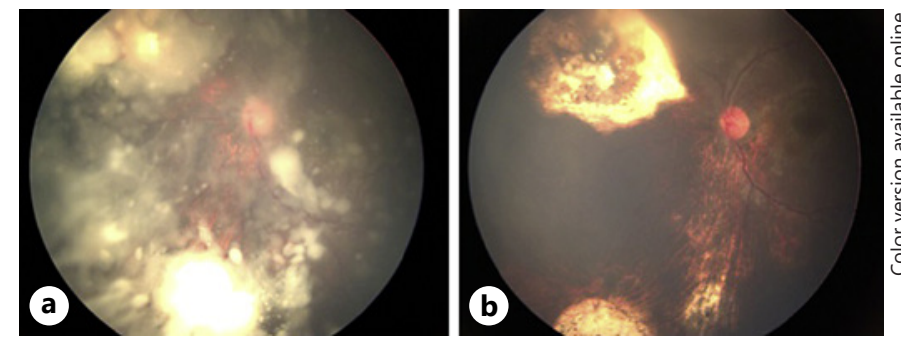

Fig. 2. Six-year-old male with bilateral $\mathrm{Rb}$ whose right eye was previously enucleated. a Group D recurrent tumor with extensive vitreous seeds. $\mathbf{b}$ Tumor and vitreous seeds regression after secondary treatment with 5 cycles of IAC plus 4 cycles of IvitC. No recurrence and visual acuity 20/70 after 23 months of follow-up. Rb, retinoblastoma; IAC, intra-arterial chemotherapy; IvitC, intra-vitreal chemotherapy.

All treatments in our study were planned and conducted by the ophthalmology and interventional neuroradiology groups simultaneously. This strategy facilitated the decision-making process, lowered the treatment costs, hospital visits, and the number of treatments requiring general anesthesia associated with neurologic adverse events $[29,30]$. We observed a higher number of catheterizations per eye when compared to other studies $[12,30]$, and this could be explained by an increased frequency of patients with advanced disease, secondary treatment and rescue IAC.

Tandem therapy was used in $16 \%$ of the patients. This has been controversial as it has been associated with high risk of micrometastasis, pineoblastoma, and secondary tumors [5]. However, other studies reported lower adverse events, higher eye salvage, and lower treatment time when compared to IVC $[27,31]$, and these results are in line with our findings in which none of the patients receiving tandem therapy showed this type of adverse events.

A low number of studies are also available assessing eye salvage rates of IAC in the IvitC era. Dalvin et al. [8] found that using IAC alone as primary treatment resulted in a salvage rate of $74 \%$. When considering primary treatment alone, this rate is similar to the one we observed (79\%). In our study cohort, patients from other countries had a lower ocular-salvage probability and higher risk of treatment failure, possibly associated with transportation and follow-up difficulties. We found that internal carotid artery access was associated with lower treatment failure and a higher ocular survival probability. This finding is in line with those of other reports [32].

One eye from group $\mathrm{C}$, which received IAC + IvitC, was enucleated as presented associated endophthalmitis.

Intra-Arterial Chemotherapy for

Retinoblastoma in Colombia
The frequency for endophthalmitis associated with intravitreal injections is $0.2 \%$, but we found a higher frequency for this adverse event, that is, $0.43 \%$ [33]. It is important to point out that, to our knowledge, this is the first report for endophthalmitis in association with IvitC.

IvitC was used in 3 single-eyes with subretinal seeds or refractory retinal disease in addition to eyes with recurrent or persistent vitreous seeds. For these eyes, continuing with IAC was not possible as 2 of th e patients had developed ophthalmic artery stenosis, while the other one showed an allergic reaction to the contrast media. Enucleation was necessary only in one of these patients as the other 2 were successfully treated with IvitC. Despite the low number of patients, we suggest the use of IvitC in cases with recurrent retinal disease in which the use of IAC is contraindicated (i.e., ophthalmic artery stenosis). A similar recommendation was done by Abramson et al. [34]. IvitC with IVC can also be an alternative for low- and middle-income countries where IAC is not available [27].

Metastasis and death occurred in 1 case in which the parents refused enucleation. This $1 \%$ mortality is similar to 1.5 and $2.5 \%$ observed in patients treated with IAC in high-income countries [26, 35, 36].

We had only 1 cerebral vascular occlusion treated with Tirofiban limiting the impairment to a level one in the modified ranking [37]. The cerebral vascular occlusion was observed in the third catheterized patient and was more likely associated with the learning curve. The most prevalent adverse events associated to IAC were frontal erythema, loss of eyelashes, and eyelid edema, similar to what has been reported elsewhere [13]. All the periocular adverse events were transitory and there were 2 cases of optic neuropathy. These adverse events were also common among other studies [12,38]. We did not have any cases of ophthalmic artery occlusion which has a prevalence of $2 \%$ in other studies [36]. No secondary tumors or pinealoblastoma were observed, but we found 5 (5.8\%) cases of neutropenia of levels 3 and 4 . This rate is between those reported elsewhere $[13,36]$, and none of them required transfusion.

Our study is limited as it is a retrospective analysis involving only 1 center and different therapies with several chemotherapeutic agents, making it challenging to analyze and compare our results with those gathered by other studies. Additionally, over half of the evaluated patients were previously treated in other institutions, and some of them had short follow-up times, particularly those coming from different countries.

In conclusion, our study is valuable as it describes the experience of treating $\mathrm{Rb}$ patients with IAC and IvitC in 
Colombia for the first time. Our results show eye salvage rates, survival rates, and adverse events comparable to those of high-income countries. It is crucial to have reference institutions with multidisciplinary teams in low and middle-income countries where there is a higher incidence of advanced disease and enucleations.

\section{Acknowledgements}

We highly value the participation of Dr. Carlos Díaz, Interventional Neuroradiologist, and Javier Fox, Hematology-Oncologist, in the tumor boards where treatments were decided. We also thank Dr. Oscar Villada from HSVF Research Department for the statistical assessment.

\section{Statement of Ethics}

Parents or guardians were informed about the procedure's risks and asked for informed consent. The HSVF Institutional Ethics Committee approved the study (No. 01-2017), which complied with the Helsinki Declaration.

\section{Conflict of Interest Statement}

None of the authors have any conflicts of interest to declare.

\section{Funding Sources}

This study did not have any funding sources from private or public institutions.

\section{Author Contributions}

María Elena González: conceptualization, methodology, formal analysis validation, writing - original draft, review, and editing - and supervision. Martha Lía Gaviria: conceptualization, methodology, formal analysis validation, writing - original draft, review, and editing - supervision. Mariana López: conceptualization, methodology, formal analysis validation, writing - original draft, review, and editing. Andrés Bravo: conceptualization and writing - original draft and formal analysis. Sergio Alberto Vargas: conceptualization, methodology, and writing - review and editing. Pablo Andrés Escudero: conceptualization, methodology, and writing - review and editing.

\section{References}

1 Pekacka A. The role of intraarterial chemotherapy in the management of retinoblastoma. J Ophthalmol. 2020;2020:3638410.

2 Abramson DH, Dunkel IJ, Brodie SE, Kim JW, Gobin YP. A phase I/II study of direct intraarterial (ophthalmic artery) chemotherapy with melphalan for intraocular retinoblastoma initial results. Ophthalmology. 2008;115(8):1398-e1.

3 Shields CL, Fulco EM, Arias JD, Alarcon C, Pellegrini M, Rishi P, et al. Retinoblastoma frontiers with intravenous, intra-arterial, periocular, and intravitreal chemotherapy. Eye. 2013;27(2):253-64.

4 Yamane T, Kaneko A, Mohri M. The technique of ophthalmic arterial infusion therapy for patients with intraocular retinoblastoma. Int J Clin Oncol. 2004;9(2):69-73.

5 Zage PE, Reitman AJ, Seshadri R, Weinstein $\mathrm{JL}$, Mets MB, Zeid JL, et al. Outcomes of a two-drug chemotherapy regimen for intraocular retinoblastoma. Pediatr Blood Cancer. 2008;50(3):567-72.

6 Turaka K, Shields CL, Meadows AT, Leahey A. Second malignant neoplasms following chemoreduction with carboplatin, etoposide, and vincristine in 245 patients with intraocular retinoblastoma. Pediatr Blood Cancer. 2012 Jul 15;59(1):121-5.

7 Abramson DH, Daniels AB, Marr BP, Francis JH, Brodie SE, Dunkel IJ, et al. Intra-arterial chemotherapy (ophthalmic artery chemosurgery) for group D retinoblastoma. PLoS One. 2016;11(1):e0146582.
8 Dalvin LA, Kumari M, Essuman VA, Shohelly Shipa S, Ancona-Lezama D, Lucio-Alvarez JA, et al. Primary intra-arterial chemotherapy for retinoblastoma in the intravitreal chemotherapy era: five years of experience. Ocul Oncol Pathol. 2019;5(2):139-46.

9 Shields CL, Alset AE, Say EA, Caywood E, Jabbour P, Shields JA. Retinoblastoma control with primary intra-arterial chemotherapy: outcomes before and during the intravitreal chemotherapy era. J Pediatr Ophthalmol Strabismus. 2016;53(5):275-84.

10 Munier FL, Gaillard MC, Balmer A, Soliman S, Podilsky G, Moulin AP, et al. Intravitreal chemotherapy for vitreous disease in retinoblastoma revisited: from prohibition to conditional indications. Br J Ophthalmol. 2012; 96(8):1078-83.

11 Singh G, Daniels AB. Disparities in retinoblastoma presentation, treatment, and outcomes in developed and less-developed countries. Semin Ophthalmol. 2016;31(4):310-6.

12 Shields CL, Manjandavida FP, Lally SE, Pieretti G, Arepalli SA, Caywood EH, et al. Intraarterial chemotherapy for retinoblastoma in 70 eyes: outcomes based on the international classification of retinoblastoma. Ophthalmology. 2014;121(7):1453-60.

13 Manjandavida FP, Stathopoulos C, Zhang J, Honavar SG, Shields CL. Intra-arterial chemotherapy in retinoblastoma: a paradigm change. Indian J Ophthalmol. 2019;67(6):740.

14 Shields CL, Say EA, Pointdujour-Lim R, Cao C, Jabbour PM, Shields JA. Rescue intra-arte- rial chemotherapy following retinoblastoma recurrence after initial intra-arterial chemotherapy. J Fr Ophtalmol. 2015;38(6):542-9.

15 Meadows A, Chintagumpala M, Dunkel I, Friedman D, Stoner J, Villablanca J. Children's oncology group (COG) trials for retinoblastoma. En: Clin Ophthalmic Oncol. 2007:491-5.

16 Shields CL, Mashayekhi A, Au AK, Czyz C, Leahey A, Meadows AT, et al. The International classification of retinoblastoma predicts chemoreduction success. Ophthalmology. 2006;113(12):2276-80.

17 Munier FL, Beck-Popovic M, Chantada GL, Cobrinik D, Kivelä TT, Lohmann D, et al. Conservative management of retinoblastoma: challenging orthodoxy without compromising the state of metastatic grace. "Alive, with good vision and no comorbidity". Prog Retin Eye Res. 2019;73:100764.

18 RStudio Team. RStudio: Integrated Development Environment for R. RStudio, PBC. Boston, MA; 2020.

19 Therneau T. A Package for Survival Analysis in R. R package version 3.2-3. 2020.

20 Kassambara A, Kosinski M, Biecek P. Survminer: Drawing Survival Curves using "ggplot2". R package version 0.4.8.999. 2020.

21 EL CONGRESO DE LA REPUBLICA DE COLOMBIA. LEY NUMERO 100 DE [Internet]. Sec. II, 100 dic 23. 1993. p. 68. Disponible en. Available from: https://www.minsalud. gov.co/sites/rid/Lists/BibliotecaDigital/ RIDE/DE/DIJ/ley-100-de-1993.pdf 
22 González M, Gaviria ML, Giraldo D, Alexandra C, Robayo JP, Fox J, et al. Retinoblastoma in Colombia. XXXIV Pan-American Asociation of Ophthalmology; 2019

23 Naseripour M. "Retinoblastoma survival disparity": the expanding horizon in developing countries. Saudi J Ophthalmol. 2012;26(2): $157-61$.

24 Lin P, O'Brien JM. Frontiers in the management of retinoblastoma. Am J Ophthalmol. 2009;148(2):192-8.

25 Fernandes AG, Pollock BD, Rabito FA. Retinoblastoma in the United States: a 40-Year incidence and survival analysis. J Pediatr Ophthalmol Strabismus. 2018;55(3):182-8.

26 MacCarthy A, Birch JM, Draper GJ, Hungerford JL, Kingston JE, Kroll ME, et al. Retinoblastoma: treatment and survival in Great Britain 1963 to 2002. Br J Ophthalmol. 2009; 93(1):38-9.

27 Funes S, Sampor C, Villasante F, Fandiño A, Manzitti J, Sgroi M, et al. Feasibility and results of an intraarterial chemotherapy program for the conservative treatment of retinoblastoma in Argentina. Pediatr Blood Cancer. 2018;65(8):e27086.
28 Leal-Leal CA, Asencio-López L, HigueraCalleja J, Bernal-Moreno M, Bosch-Canto V, Chávez-Pacheco J, et al. Globe salvage with intra-arterial topotecan-melphalan chemotherapy in children with a single eye. Rev Invest Clin. 2016;68(3):137-42.

29 Habre W, Disma N, Virag K, Becke K, Hansen TG, Jöhr M, et al. Incidence of severe critical events in paediatric anaesthesia (APRICOT): a prospective multicentre observational study in 261 hospitals in Europe. Lancet Respir Med. 2017;5(5):412-25.

30 Suzuki S, Yamane T, Mohri M, Kaneko A. Selective ophthalmic arterial injection therapy for intraocular retinoblastoma: the long-term prognosis. Ophthalmology. 2011;118(10): 2081-7.

31 Abramson DH, Marr BP, Francis JH, Dunkel IJ, Fabius AWM, Brodie SE, et al. Simultaneous bilateral ophthalmic artery chemosurgery for bilateral retinoblastoma (Tandem Therapy). PLoS One. 2016 Jun 3;11(6):e0156806.

32 Sweid A, Hammoud B, Texakalidis P, Xu V, Shivashankar K, Baldassari MP, et al. The use of alternative routes for the delivery of intraarterial chemotherapy for retinoblastoma. Neurosurgery. 2020 Oct 15;87(5):956-963.
33 Jager RD, Aiello LP, Patel SC, Cunningham ET. Risks of intravitreous injection: a comprehensive review. Retina. 2004;24(5):67698.

34 Abramson DH, Ji X, Francis JH, Catalanotti F, Brodie SE, Habib L. Intravitreal chemotherapy in retinoblastoma: expanded use beyond intravitreal seeds. Br J Ophthalmol. 2019;103(4):488-93.

35 Yousef YA, Soliman SE, Astudillo PP, Durairaj P, Dimaras H, Chan HS, et al. Intra-arterial chemotherapy for retinoblastoma: a systematic review. JAMA Ophthalmol. 2016; 134(5):584-91.

36 Ravindran K, Dalvin LA, Pulido JS, Brinjikji $\mathrm{W}$. Intra-arterial chemotherapy for retinoblastoma: an updated systematic review and meta-analysis. J Neurointerv Surg. 2019; 11(12):1266-72.

37 van Swieten JC, Koudstaal PJ, Visser MC, Schouten HJ, van Gijn J. Interobserver agreement for the assessment of handicap in stroke patients. Stroke. 1988;19(5):604-7.

38 Akyüz C, Kıratlı H, Şen H, Aydın B, Tarlan B, Varan A. Intra-arterial chemotherapy for retinoblastoma: a single-center experience. Ophthalmologica. 2015;234(4):227-32. 